\title{
DESA WISATA MENJADI KEKUATAN BARU EKONOMI DESA
}

\section{VILLAGE TOURISM BECOME A NEW ECONOMIC POWER OF THE VILLAGE}

\author{
Wa Afrianti ${ }^{1}$, Rostina ${ }^{2}$, La Ode Muhammad Ilham ${ }^{3}$, Eka Setia Ningsih ${ }^{4}$, \\ Muhammad Rizal Ardiansah Putra ${ }^{5}$, Herman Lawelai ${ }^{6}$ \\ ${ }^{12}$ Mahasiswa Program Studi Ilmu Komunikasi \\ ${ }^{34}$ Mahasiswa Program Studi Ilmu Pemerintahan \\ ${ }^{5}$ Dosen Program Studi Ilmu Komunikasi, Fakultas Ilmu Sosial dan Ilmu Politik \\ ${ }^{6}$ Dosen Program Studi Ilmu Pemerintahan, Fakultas Ilmu Sosial dan Ilmu Politik \\ Universitas Muhammadiyah Buton \\ ${ }^{5}$ Email: Icalard21@gmail.com
}

\begin{abstract}
Abstrak: Program pengabdian masyarakat ini dilakukan di Desa Mopaano Kecamatan Lasalimu Selatan Kabupaten Buton. Program pengabdian masyarakat ini menyimpulkan bahwa peran modal sosial dapat digunakan untuk masyarakat dalam bentuk pengetahuan lokal, yang kemudian dapat dimanfaatkan sebagai sarana pendampingan, pembinaan, pengelolaan pariwisata dan arahan pengembangan objek wiata kepada pemerintah desa dan masayarakat Desa Mopaano. Dengan dikelolanya object wisata di Desa Mopaano ini akan mendorong laju perekonomian rakyat, karena dengan adanya tujuan wisata di Desa ini akan mampu mempromosikan semua sektor sektor ekonomi yang ada di desa, baik itu dari kerajinan, pertanian, dan budaya.
\end{abstract}

Kata kunci: Desa Wisata, Modal Sosial

Abstract: This community service program is carried out in Mopaano Village, Lasalimu Selatan District, Buton Regency. This community service program concluded that the role of social capital can be used for the community in the form of local knowledge, which can then be used as a means of assistance, guidance, tourism management and direction for the development of wiata objects to the village government and Mopaano Village community. With the management of tourism objects in the village of Mopaano this will drive the pace of the people's economy, because with the existence of a tourist destination in the village will be able to promote all sectors of the economic sector in the village, be it from crafts, questions, and culture.

Keywords: Tourism Village, Social Capital

\section{PENDAHULUAN}

Dalam konteks pendanaan Desa harus mampu menyusun program kerja dan mempertanggungjawabkan Anggaran Pendapatan dan Belanja pemerintah desa (APBDesa) yang secara garis besar terdiri dari belanja dan pendapatan desa. Dalam hal pengelolaan Pendapatan, desa berhak mengelola dan menggali potensipotensi yang terdapat didesanya sehingga dapat meningkatkan Pendapatan Asli Desa (PADes). Salah satu potensi yang dapat ditingkatkan menjadi Pendapatan 


\section{INTEGRITAS : Jurnal Pengabdian}

Vol 4, No 2, Desember 2020

ISSN 2580 - 7978 (cetak) ISSN 2615 - 0794 (online)

Asli Desa (PADes) di Indonesia adalah sektor pariwisata. Pengembangan sektor pariwisata sebagai salah satu bagian dari pengembangan sektor ekonomi kreatif saat ini menjadi salah satu program prioritas pembangunan pemerintah pusat (Listriyana \& Pahlewi, 2019).

Desa wisata adalah sebuah kawasan pedesaan yang memiliki beberapa karakteristik khusus untuk menjadi daerah tujuan wisata. Di kawasan ini, penduduknya masih memiliki tradisi dan budaya yang relatif masih asli. Selain itu, beberapa faktor pendukung seperti makanan khas, sistem pertanian dan sistem sosial turut mewarnai sebuah kawasan desa wisata. Di luar faktor-faktor tersebut, alam dan lingkungan yang masih asli dan terjaga merupakan salah satu faktor terpenting dari sebuah kawasan tujuan wisata (Zakaria \& Suprihardjo, 2014).

Prinsip pengembangan desa wisata adalah sebagai salah satu produk wisata alternatif yang dapat memberikan dorongan bagi pembangunan pedesaan yang berkelanjutan serta memiliki prinsip-prinsip pengelolaan antara lain, ialah: (1) memanfaatkan sarana dan prasarana masyarakat setempat, (2) menguntungkan masyarakat setempat, (3) berskala kecil untuk memudahkan terjalinnya hubungan timbal balik dengan masyarakat setempat, (4) melibatkan masyarakat setempat, (5) menerapkan pengembangan produk wisata pedesaan, dan beberapa kriteria yang mendasarinya seperti antara lain: 1. Penyediaan fasilitas dan prasarana yang dimiliki masyarakat lokal yang biasanya mendorong peran serta masyarakat dan menjamin adanya akses ke sumber fisik merupakan batu loncatan untuk berkembangnya desa wisata; 2 . Mendorong peningkatan pendapatan dari sektor pertanian dan kegiatan ekonomi tradisional lainnya; 3. Penduduk setempat memiliki peranan yang efektif dalam proses pembuatan keputusan tentang bentuk pariwisata yang memanfaatkan kawasan lingkungan dan penduduk setempat memperoleh pembagian pendapatan yang pantas dari kegiatan pariwisata; dan 4 . Mendorong perkembangan kewirausahaan masyarakat setempat (Out et al., 2010).

Desa yang juga memiliki potensi untuk dikelola dan dikembangkan berdasarkan prinsip-prinsip pariwisata berkelanjutan, yaitu Desa Mopaano Kecamatan Lasalimu Selatan Kabupaten Buton. Letaknya sekitar 50km dari pusat 


\section{INTEGRITAS : Jurnal Pengabdian}

Vol 4, No 2, Desember 2020

ISSN $2580-7978$ (cetak) ISSN 2615 - 0794 (online)

Kota Pasarwajo. Desa Mopaano memiliki sumber daya alam yang potensial, ada dua objek wisata alam yaitu Pantai Koguna dan Danau Udang Merah. Potensi pariwisata di Desa Mopaano masih perlu dikembangkan.
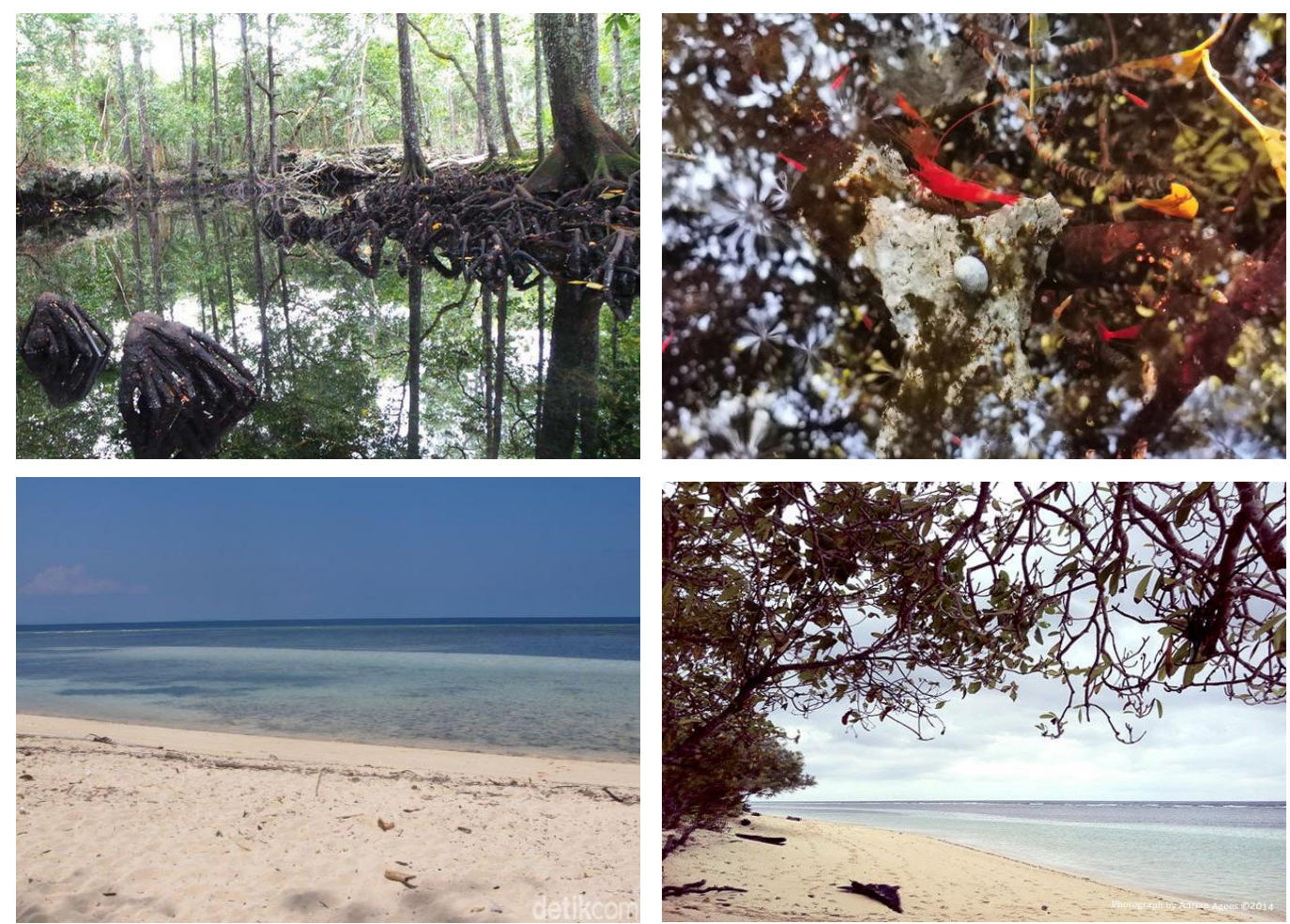

Gambar 1. Danau Udang Merah dan Pantai Koguna

Pengembangan produk unggulan desa sebagai program yang harus di jalankan, selain pertanian destinasi wisata merupakan salah satu sektor kekuatan untuk perekonomian desa. Desa dapat mengembangkan potensi pariwisatanya sebagai produk unggulan. Di dalam dunia kepariwisataan sekarang terdapat kecenderungan untuk mengolah potensi daerah.

Kegiatan PKM ini dilaksanakan oleh dosen dan mahasiwa Fakultas Ilmu Sosial dan Ilmu Politik Universitas Muhammadiyah Buton. Kegiatan pengabdian ini tidak hanya sebagai perwujudan tanggung jawab dosen dalam hal tridharma perguruan tinggi yang dilaksanakan rutin setiap tahun pada masyarakat, melainkan juga sebagai sebuah kegiatan yang memberikan pengalaman kepada mahasiswa untuk belajar dan menerapkan keterampilan sesuai bidang keahlian 


\section{INTEGRITAS : Jurnal Pengabdian}

Vol 4, No 2, Desember 2020

ISSN $2580-7978$ (cetak) ISSN 2615 - 0794 (online)

yang di pelajari untuk di terapkan kepada masyarakat. Kegiatan ini tentunya akan menambah wawasan sekaligus melengkapi keterampilan dosen dan mahasiswa.

Kegiatan pengabdian kepada masyarakat (PKM) ini diselenggarakan di Desa Mopaano Kecamatan Lasalimu Selatan Kabupaten Buton, adapun tujuan dari pengabdian masyarakat dilaksanakan ialah untuk memberikan pendampingan pembinaan pengelolaan pariwisata dan arahan pengembangan pariwisata.

Adapun output yang menjadi target dalam pengabdian ini adalah Perangkat Desa dan masyarakat Desa Mopaano mempunyai keterampilan dalam mengelolaan pariwisata dan arahan pengembangan pariwisata.

\section{METODE}

Pengabdian masyarakat ini dilaksanakan melalui pendekatan modal sosial, sebab hal ini lebih mudah ditemukan dalam masyarakat yang lebih menonjol dalam ikatan budaya, kekerabatan dan lingkungan. Dengan begitu, pendekatan modal sosial memungkinkan adanya ikatan timbal balik dari dan kepada masyarakat lokal tersebut. Modal sosial sebagai perekat sosial (social glue) pada komunitas masyarakat. olehnya itu, modal sosial tersebut akan sangat ditentukan sebagai akumulasi dari beragam tipe dari aspek sosial, psikologi, budaya, kelembagaan, dan aset yang tidak terlihat (intangible) yang mempengaruhi perilaku kerjasama (Arya Maulana Wijaya et al., 2019).

Dengan deskripsi modal sosial seperti diatas, dipercaya bahwa pendekatan seperti itu dapat dijadikan salah satu sarana untuk memberikan pendampingan pembinaan pengelolaan pariwisata dan arahan pengembangan pariwisata kepada pemerintah desa dan masayarakat Desa Mopaano. Melalui, kondisi masyarakat Desa Mopaano yang masih memegang erat kehidupan dan pengalaman budaya, serta kehidupan gotong royong masyarakatnya. Maka pendekatan budaya dan komunitas, memungkinkan adanya kolaborasi antara input kebijakan.

\section{HASIL DAN PEMBAHASAN}

Potensi objek wisata Desa Mopaano memiliki daya tarik wisata yang hingga saat ini belum dikembangkan. Potensi wisata di Desa Mopaano secara garis besar 


\section{INTEGRITAS : Jurnal Pengabdian}

Vol 4, No 2, Desember 2020

ISSN $2580-7978$ (cetak) ISSN 2615 - 0794 (online)

adalah wisata alam. Potensi wisata alam terdiri dari beberapa potensi objek wisata yaitu Danau Udang Merah dan Pantai Koguna.

Kekayaan potensi wisata Desa Mopaano perlu untuk diarah-kembangkan supaya dapat mendukung pariwisata berkelanjutan. Rekomendasi yang dapat diberikan untuk mengembangkan potensi wisata di Desa Mopaano diarahkan berdasarkan kondisi Desa Mopaano yang statusnya dijadikan sebagai desa wisata, namun kondisi ini tidaklah mudah. Hal tersebut harus ditunjukkan dengan pengelolaan dan Pengembangann pariwisata, padahal Desa Mopaano memiliki potensi wisata yang cukup menarik.

Dengan dikelolanya obyek wisata di Desa Mopaano ini akan mendorong laju perekonomian rakyat, karena dengan adanya tujuan wisata di Desa ini akan mampu mempromosikan semua sektor sektor ekonomi yang ada di desa, baik itu dari kerajinan, pertanian, dan budaya.

\section{Tabel 1}

Tahapan Kegiatan Pengabdian

\begin{tabular}{|c|c|c|c|}
\hline No & Tahapan Kegiatan & $\begin{array}{l}\text { Metode yang } \\
\text { Digunakan }\end{array}$ & Keterangan \\
\hline 1 & $\begin{array}{l}\text { Survey dan Penetapan Wilayah } \\
\text { Mitra }\end{array}$ & Pertemuan dan diskusi & $\begin{array}{l}\text { Tim PKM dan } \\
\text { Kepala Desa, }\end{array}$ \\
\hline 2 & $\begin{array}{lr}\text { Pelaksanaan } & \text { Kegiatan } \\
\text { Penyampaian Materi } & \text { Tentang } \\
\text { Desa } \quad \text { Wisata } & \text { Menjadi } \\
\text { Kekuatan Baru Ekonomi Desa }\end{array}$ & $\begin{array}{l}\text { Pertemuan, Ceramah } \\
\text { dan diskusi }\end{array}$ & $\begin{array}{l}\text { Tim PKM, Aparatur } \\
\text { Perangkat desa, } \\
\text { Kepala Dusun dan } \\
\text { Masyarakat }\end{array}$ \\
\hline 3 & $\begin{array}{l}\text { Pendampingan Pengembangan } \\
\text { Obyek Wisata }\end{array}$ & $\begin{array}{l}\text { Mendampingi dalam } \\
\text { Pengembangan Obyek } \\
\text { Wisata }\end{array}$ & $\begin{array}{l}\text { Tim PKM, Aparatur } \\
\text { perangkat desa, dan } \\
\text { Masyarakat }\end{array}$ \\
\hline
\end{tabular}




\section{INTEGRITAS : Jurnal Pengabdian}

Vol 4, No 2, Desember 2020

ISSN $2580-7978$ (cetak) ISSN 2615 - 0794 (online)

Penjelasan Tahapan Kegiatan Pengabdian Kepada Masyarakat (PKM) yang dilakukan TIM PKM adalah sebagai berikut:

1. Survey dan Penetapan Wilayah Mitra

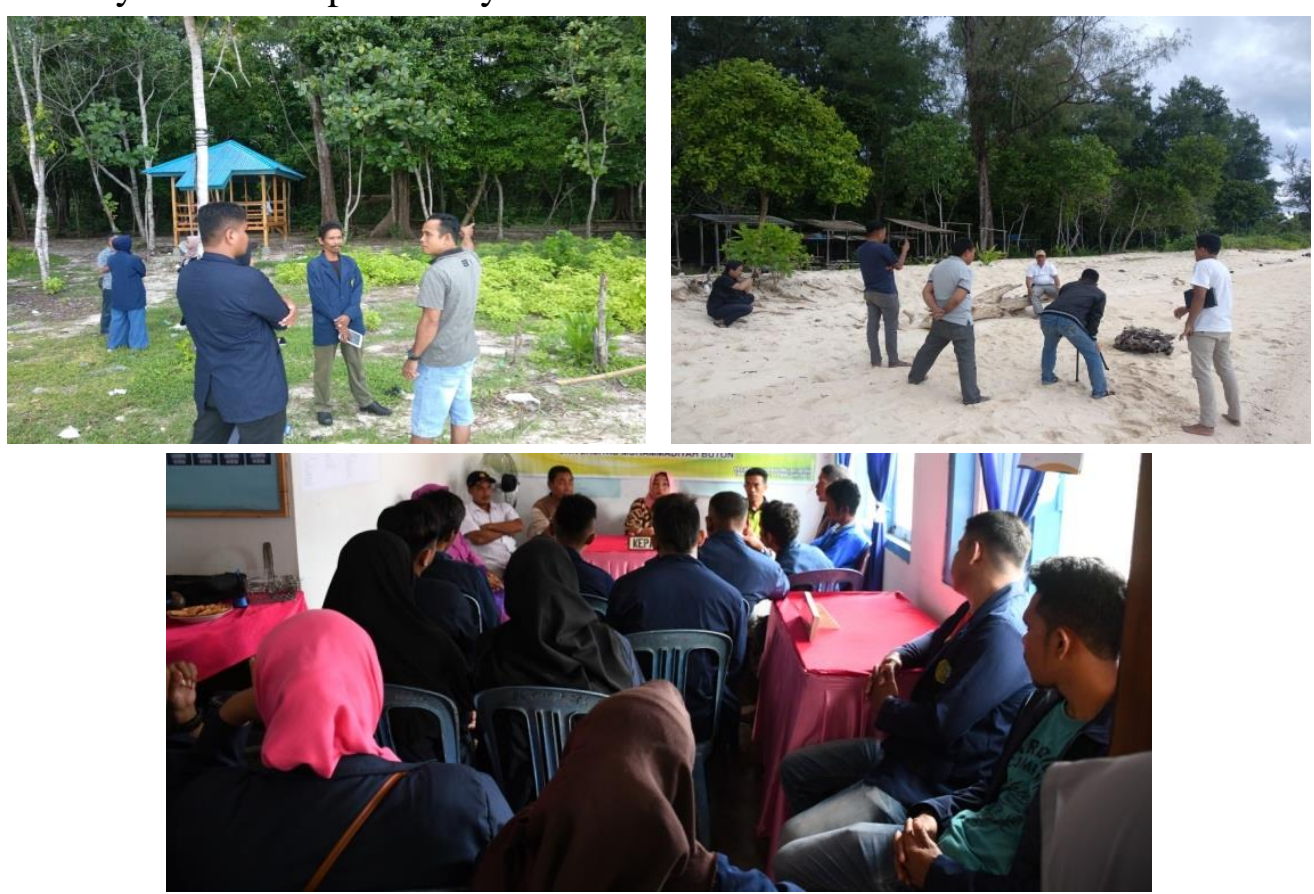

Gambar 2. Survey dan Penetapan Wilayah Mitra

Tujuan Umum melakukan Survey lapangan adalah untuk mengamati secara langsung lokasi wilayah mitra. Kegiatan pengamatan dilakukan guna menggali dan mengumpulkan data yang diperlukan bagi topik pembahasan guna pengembangan wawasan dan peningkatan kinerja bagi para peserta PKM. Tujuan survey lapangan adalah agar memahami tentang pengumpulan data/informasi, dapat mengetahui cara mengumpulkan data/informasi. Survey lapangan dilakukan secara kelompok

2. Pelaksanaan Kegiatan Penyampaian Materi Tentang Desa Wisata Menjadi Kekuatan Baru Ekonomi Desa

Tahap Penyampaian Materi Tentang Desa Wisata Menjadi Kekuatan Baru Ekonomi Desa, dilaksanakan di dibalai pertemuan Desa Mopaano, pertemuan dihadiri oleh kepala Desa, Kepala Dusun, dan masyarakat Desa Mopaano. 

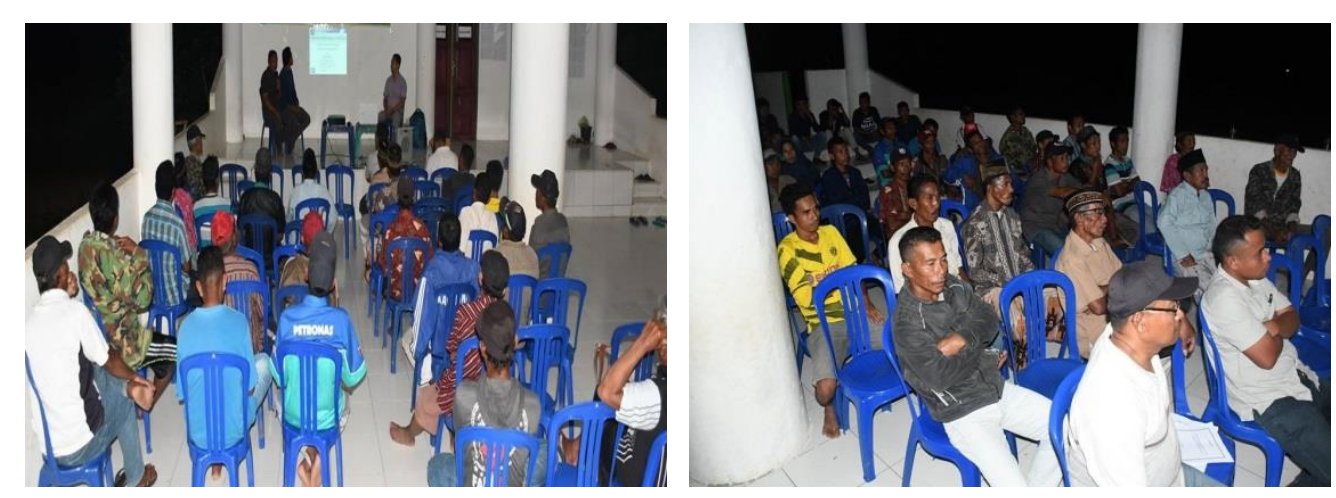

Gambar 3. Penyampaian Materi Desa Wisata Menjadi Kekuatan Baru Ekonomi Desa

Kegiatan ini memberikan pemahaman mengenai Pengelolaan pariwisata berbasis komunitas merupakan suatu alat pembangunan dalam masyarakat guna meningkatkan peran masyarakat agar berpartisipasi aktif untuk mengelola pariwisata dan terlibat secara penuh dalam pengelolaan tersebut. Penilaian pengelolaan pariwisata berbasis komunitas mengacu pada beberapa indikator yang menjadi dasar untuk mengetahui pengelolaan wisata berbasis komunitas, yaitu pengelolaan atraksi wisata, fasilitas, aksesibilitas, promosi, kemitraan, pemberdayaan masyarakat serta kondisi alam, sosial, ekonomi, dan budaya.

\section{Pendampingan}

Setelah dilaksanakannya penyampaian materi dilanjutkan dengan metode pendampingan yang mana kegiatan ini memberi penjelasan tentang bagaimana meningkatkan pengunjung untuk berwisata di Desa Mopaano. Desa Mopaano harus menyediakan media promosi sebagai pengenal kawasan wisata di Desa Mopaano ke masyarakat luar, Pengelolaan dari masyarakat setempat agar ikut berperan aktif dalam pengembangan kawasan desa wisata, dan Kebijakan pemerintah dalam mengontrol pengembangan kawasan desa wisata di Desa Mopaano.

Setelah itu bersama-sama mencari solusi rencana tindak lanjut dalam menentukan berapa biaya penyediaan sarana dan prasana yang harus disiapkan di wilayah objek wisata, seperti tong sampah, membuat WC umum, dan gazebo ini dilakukan secara gotong royong yang telah disediakan oleh pemerintah agar layak untuk digunakan bagi pengunjung. 


\section{INTEGRITAS : Jurnal Pengabdian}

Vol 4, No 2, Desember 2020

ISSN 2580 - 7978 (cetak) ISSN 2615 - 0794 (online)

\section{KESIMPULAN}

Potensi obyek wisata Desa Mopaano memiliki daya tarik wisata yang hingga saat ini belum dikembangkan. Potensi wisata yang ada di Desa Mopaano adalah wisata alam yaitu Danau Udang Merah dan Pantai Koguna.

Pengelolaan pariwisata di Desa Mopaano masih kurang optimal. Terdapat Beberapa aspek, terutama Pengembangann sumberdaya manusia yang perlu diarah kembangkan untuk mendukung pengembangan pariwisata di Desa Mopaano,

Program pengabdian masyarakat ini menyimpulkan bahwa peran modal sosial dapat digunakan untuk masyarakat dalam bentuk pengetahuan lokal, yang kemudian dapat dimanfaatkan sebagai sarana pendampingan, pembinaan, pengelolaan pariwisata dan arahan pengembangan obyek wiata kepada pemerintah desa dan masayarakat Desa Mopaano. Proses meningkatkan pengetahuan masyarakat dalam pengembangan desa wisata dilaksanakan melalui: survey lokasi, Penyampaian Materi Tentang Desa Wisata Menjadi Kekuatan Baru Ekonomi Desa, pendampingan dan tindak lanjut penyediaan sarana dan prasana yang harus disiapkan diarea obyek wisata untuk menearik wisatawan.

\section{DAFTAR PUSTAKA}

Arya Maulana Wijaya, A., Sadat, A., Azhar Sa, L., Suherman, A., Fajar Maulana, H., \& Rizal Ardiansah Putra, M. (2019). Pemanfaatan Modal Sosial Dalam Penguatan Program Desa Tangguh Bencana. Jurnal Pengabdian Kepada Masyarakat MEMBANGUN NEGERI, 2(1), 1-13.

Listriyana, A., \& Pahlewi, A. D. (2019). INTEGRITAS: Jurnal Pengabdian INTEGRITAS : Jurnal Pengabdian. 3(1), 42-54.

Out, H., Kuliah, M., Resort, C., Pengembangan, S., \& Pengelolaan, D. A. N. (2010). Konsep pengembangan kawasan desa wisata 1. 1-36.

Zakaria, F., \& Suprihardjo, D. (2014). Konsep Pengembangan Kawasan Desa Wisata di Desa Bandungan Kecamatan Pakong Kabupaten Pamekasan. Teknik Pomits, 3(2), C245-C249. https://doi.org/2337-3520 